\title{
Emergence of a novel cluster of influenza A(H5N1) virus clade 2.2.1.2 with putative human health impact in Egypt, 2014/15
}

A S Arafa ${ }^{1,2}$, M M Naguib ${ }^{1,2,3}$, C Luttermann³, A A Selim¹, W H Kilany ${ }^{1}$, N Hagag ${ }^{1}$, A Samy ${ }^{1}$, A Abdelhalim ${ }^{1}$, M K Hassan $^{1}$, E M

Abdelwhab ${ }^{1}$, Y Makonnen, , G Dauphin ${ }^{5}$, J Lubroth5 ${ }^{5}$, T C Mettenleiter $^{3}$, M Beer $^{3}$, C Grund $^{3}$, T C Harder (timm.harder@fli.bund.de)3

1. National Laboratory for Veterinary Quality Control on Poultry Production, Animal Health Research Institute, Dokki, Giza, Egypt

2. These authors have contributed equally

3. Friedrich-Loeffler-Institut, Federal Research Institute for Animal Health, Greifswald Insel-Riems, Germany

4. Food and Agriculture Organization of the United Nations (FAO), Emergency Centre for Transboundary animal Diseases (ECTAD), Cairo, Egypt

5. Food and Agriculture Organisation of the United Nations (FAO), Animal Production and Health division, Viale delle Terme di Caracalla, Rome, Italy

Arafa AS, Naguib MM, Luttermann C, Selim AA, Kilany WH, Hagag N, Samy A, Abdelhalim A, Hassan MK, Abdelwhab EM, Makonnen Y, Dauphin G, Lubroth J,

Mettenleiter TC, Beer M, Grund C, Harder TC. Emergence of a novel cluster of influenza $A\left(\mathrm{H}_{5} \mathrm{~N}_{1}\right)$ virus clade 2.2.1.2 with putative human health impact in Egypt, 2014/15. Euro Surveill. 2015;20(13):pii=21085. Available online: http://www.eurosurveillance.org/ViewArticle.aspx?Articleld=21085

A distinct cluster of highly pathogenic avian influenza viruses of subtype $A\left(\mathrm{H}_{5} \mathrm{~N}_{1}\right)$ has been found to emerge within clade 2.2.1.2 in poultry in Egypt since summer 2014 and appears to have quickly become predominant. Viruses of this cluster may be associated with increased incidence of human influenza $A\left(\mathrm{H}_{5} \mathrm{~N}_{1}\right)$ infections in Egypt over the last months.

In Egypt, highly pathogenic avian influenza (HPAl) influenza $A\left(\mathrm{H}_{5} \mathrm{~N}_{1}\right)$ viruses of clade 2.2 .1 and their descendants have been circulating in poultry populations since 2006, causing sporadic human infections [1]. Human influenza $A\left(\mathrm{H}_{5} \mathrm{~N}_{1}\right)$ infections in Egypt have been reported since the introduction of the virus in 2006 with 204 cases occurring until end of 2014 and a fatality rate of $35,8 \%$ in laboratory-confirmed cases reported to the World Health Organization (WHO). However, since January 2015, the incidence of human $\mathrm{H}_{5} \mathrm{~N}_{1}$ cases in Egypt has increased dramatically: as of 21 March 2015, 116 human cases including 36 deaths have been reported to WHO [2]. This study was initiated to analyse molecular properties of $\mathrm{H}_{5} \mathrm{~N}_{1}$ viruses that have caused outbreaks in poultry in Egypt since summer 2014 and to compare them with published sequences from $\mathrm{H}_{5} \mathrm{~N}_{1}$ viruses obtained from recent human cases.

\section{Sample origin}

Between October 2014 and February 2015, a new wave of 435 outbreaks of $\mathrm{H}_{5} \mathrm{~N}_{1}$ infections in poultry in Egypt was reported to the National Laboratory for Quality Control on Poultry Production (NLQP) by Egyptian veterinary authorities (Figure 1). Affected poultry species included chickens, ducks, turkeys and quails on commercial farms as well as in backyard holdings. In this study, $29 \mathrm{H}_{5} \mathrm{~N}_{1}$-positive samples, mostly obtained by passive surveillance and submitted to NLQP for routine analysis, were selected so as to represent different poultry species, sectors of poultry holdings (commercial farms, backyards and live bird markets) and locations (Table 1).

\section{Phylogenetic analyses}

Nucleotide sequence data for the haemagglutinin (HA) gene of all 29 viruses and of the neuraminidase (NA) gene of 15 viruses were generated by Sanger sequencing; whole genome sequencing was carried out for four virus isolates selected to represent different locations, moments in time and sectors of poultry holdings.

Phylogenetic analysis of the HA and NA gene sequences was done with the maximum likelihood methodology using the IQTree software [3,4]. The authors gratefully acknowledge the originating and submitting laboratories who contributed sequences used in the phylogenetic analysis to the Global Initiative on Sharing All Influenza Data (GISAID) EpiFlu database, and recognise in particular Alice Fusaro and colleagues (Istituto Zooprofilattico Sperimentale Delle Venezie, Padova, Italy) as well as Mee Poh (Centers for Disease Control and Prevention, WHO Collaborating Center for Surveillance, Epidemiology and Control of Influenza, Influenza Division, Atlanta, United States). Phylogenetic analysis placed the $\mathrm{H}_{5} \mathrm{~N}_{1}$ viruses sequenced in this study into a separate cluster within the previously defined clade 2.2.1.2 (Figure $2 \mathrm{~A}$ and $2 \mathrm{~B}$ ). While the $\mathrm{H}_{5} \mathrm{~N}_{1}$ isolate $\mathrm{A} /$ duck/Egypt/14VIR784-4-133AD/2013 (KP035030) harboured the closest related ancestral sequences of this cluster, two further poultry viruses sampled in June and July 2014 were placed directly at the root of this cluster: A/quail/Egypt/BSU5514-AR2219/2014 (EPI557138) was at the basis of the HA phylogeny while $A /$ duck/ 
Influenza A(H5N1) viruses included in this study and collected from poultry, Egypt, June 2014-January 2015 (n=29)

\begin{tabular}{|c|c|c|c|c|c|c|}
\hline No & Sample ID & Sequenced & Collection date & Governorate & Source & $\begin{array}{l}\text { Accession } \\
\text { number } \\
\text { (EpiFlu) }\end{array}$ \\
\hline 1 & A/turkey/Egypt/14139FAOS/2014 & Whole genome & 18 Jun 2014 & Assiut & LBM & $\mathrm{EPI}_{574374-81}$ \\
\hline 2 & A/duck/Egypt/14154FAOS/2014 & HA, NA & 25 Jun 2014 & Monofiya & LBM & $\mathrm{EPI}_{573331-2}$ \\
\hline 3 & A/chicken/Egypt/1427AF/2014 & $\mathrm{HA}$ & 3 Sep 2014 & Fayoum & farm & $\mathrm{EPI}_{573333}$ \\
\hline 4 & A/chicken/Egypt/1476CA/2014 & $\mathrm{HA}$ & 14 Oct 2014 & Al-Gharbiya & Household & EPI573330 \\
\hline 5 & A/turkey/Egypt/AR235-S240NLQP/2014 & $\mathrm{HA}, \mathrm{NA}$ & 31 Oct 2014 & Cairo & Household & EPI573251-2 \\
\hline 6 & A/turkey/Egypt/14240FAOS/2014 & Whole genome & 31 Oct 2014 & Cairo & LBM & EPI574382-89 \\
\hline 7 & A/chicken/Egypt/141/2014 & $\mathrm{HA}$ & 3 Nov 2014 & Aswan & Household & EPI573334 \\
\hline 8 & A/duck/Egypt/14227FAOS/2014 & $\mathrm{HA}$ & 4 Nov 2014 & Sohag & Household & EPI573335 \\
\hline 9 & A/chicken/Egypt/ AR234-FAOF8NLQP/2014 & HA, NA & 12 Nov 2014 & Menia & Farm & EPI573249-50 \\
\hline 10 & A/chicken/Egypt/ AR231-CA113NLQP/2014 & HA, NA & 19 Nov 2014 & Suez & Household & $\mathrm{EPI}_{573243-4}$ \\
\hline 11 & A/chicken/Egypt/1478CAL/2014 & $\mathrm{HA}$ & 23 Nov 2014 & Qena & Household & EPI573318 \\
\hline 12 & A/duck/Egypt/144/2014 & $\mathrm{HA}$ & 4 Dec 2014 & Giza & Household & EPI573323 \\
\hline 13 & A/chicken/Egypt/14140CA/2014 & HA & 5 Dec 2014 & Assiut & Household & EPI573329 \\
\hline 14 & A/turkey/Egypt/ AR238-SD177NLQP/2014 & Whole genome & 6 Dec 2014 & El-Beheira & Household & EPI573261-8 \\
\hline 15 & A/chicken/Egypt/14148CA/2014 & $\mathrm{HA}$ & 9 Dec 2014 & Menia & Household & EPI573314 \\
\hline 16 & A/duck/Egypt-BS/146RS-f6/2014 & $\mathrm{HA}$ & 14 Dec 2014 & Beni Suef & Farm & $\mathrm{EPI} 573315$ \\
\hline 17 & A/duck/Egypt/1427SL/2014 & $\mathrm{HA}$ & 14 Dec 2014 & Sohag & Household & EPI573316 \\
\hline 18 & A/chicken/Egypt/AR233-S283NLQP/2014 & $\mathrm{HA}, \mathrm{NA}$ & 15 Dec 2014 & Qena & Household & $\mathrm{EPI}_{573247-8}$ \\
\hline 19 & A/chicken/Egypt/14168CA/2014 & $\mathrm{HA}, \mathrm{NA}$ & 16 Dec 2014 & Menia & Household & EPI573327-8 \\
\hline 20 & A/duck/Egypt/ AR232-A13NLQP/2014 & $\mathrm{HA}, \mathrm{NA}$ & 22 Dec 2014 & Giza & Household & $E P I 573245-6$ \\
\hline 21 & A/chicken/Egypt/152RS/2015 & $\mathrm{HA}$ & 29 Dec 2014 & Monofiya & Household & EPI573322 \\
\hline 22 & A/chicken/Egypt/152/2015 & $\mathrm{HA}$ & 1 Jan 2015 & South Sinai & Household & $\mathrm{EPI}_{573319}$ \\
\hline 23 & A/chicken/Egypt/153AF/2015 & $\mathrm{HA}, \mathrm{NA}$ & 4 Jan 2015 & Fayoum & Household & EPI573320-1 \\
\hline 24 & A/chicken/Egypt/1540S/2015 & $\mathrm{HA}, \mathrm{NA}$ & $11 \operatorname{Jan} 2015$ & Assiut & Household & EPI573336-7 \\
\hline 25 & A/chicken/Egypt/152Al/2015 & $\mathrm{HA}, \mathrm{NA}$ & $11 \operatorname{Jan} 2015$ & Ismailia & Household & EPI573325-6 \\
\hline 26 & A/chicken/Egypt/1510CA/2015 & $\mathrm{HA}, \mathrm{NA}$ & $14 \operatorname{Jan} 2015$ & Cairo & Household & EPI573312-3 \\
\hline 27 & A/duck/Egypt/AR236-A3NLQP/2015 & Whole genome & $15 \operatorname{Jan} 2015$ & Giza & Household & EPI573253-60 \\
\hline 28 & A/duck/Egypt/156oS/2015 & $\mathrm{HA}$ & $18 \operatorname{Jan} 2015$ & Dakahliya & Household & EPI573324 \\
\hline 29 & A/chicken/Egypt/1575S/2015 & $\mathrm{HA}$ & $21 \mathrm{Jan} 2015$ & Assiut & Household & $\mathrm{EPI}_{573317}$ \\
\hline
\end{tabular}

HA: haemagglutinin; LBM: live bird market; NA: neuraminidase.

Egypt/14154-FAOS/2014 (EPI573331) marked the basis of the NA tree (Figure $2 \mathrm{~A}$ and $2 \mathrm{~B}$, green colour). The cluster has expanded since October 2014; the fact that no more sequences of the older range of 2.2.1.2 viruses were detected thereafter indicates that this cluster had become predominant over previously circulating phylotypes. GenBank sequences of two recent $\mathrm{H}_{5} \mathrm{~N}_{1} \mathrm{HPAl}$ viruses obtained from infected humans in Egypt in November 2014 (AJM70734 and AJM70746), fell into the same expanding cluster (Figure $2 \mathrm{~A}$ and $2 \mathrm{~B}$, blue colour). Calculation of the time to the most recent common ancestor (TMRCA) of the emerging phylotype by BEAST analysis (Figure $2 \mathrm{C}$ ) [5] suggested that ancestors of this phylotype emerged around February 2014. Similar phylogenetic relationships were observed for the internal gene segments of these viruses (data not shown, available from authors upon request). The phylogenetic information of the internal genes supports the results for the HA and NA gene sequences, indicating that the new viruses represent a distinct cluster that originated from previously circulating viruses of clade 2.2.1.2. So far, no reassortment events were found to be involved in generating this newly emerging phylotype.

\section{Genetic characterisation}

Compared with viruses sampled before October 2014 in Egypt, the emerging cluster contained distinct fixed mutations in several genome segments (PB2, PB1-F2, $\mathrm{HA}, \mathrm{NA}, \mathrm{M} 1$ ).

In the HA gene, differences in the nucleotide composition of the coding sequence of up to $1.3 \%$ were found, which included up to 14 specific fixed nucleotide substitutions distinguishing these viruses from earlier 


\section{FIGURE 1}

Temporal (graph) and geographic (map) distribution of outbreaks of highly pathogenic avian influenza A(H5N1) in poultry, Egypt, October 2014-February $2015(\mathrm{n}=435)$

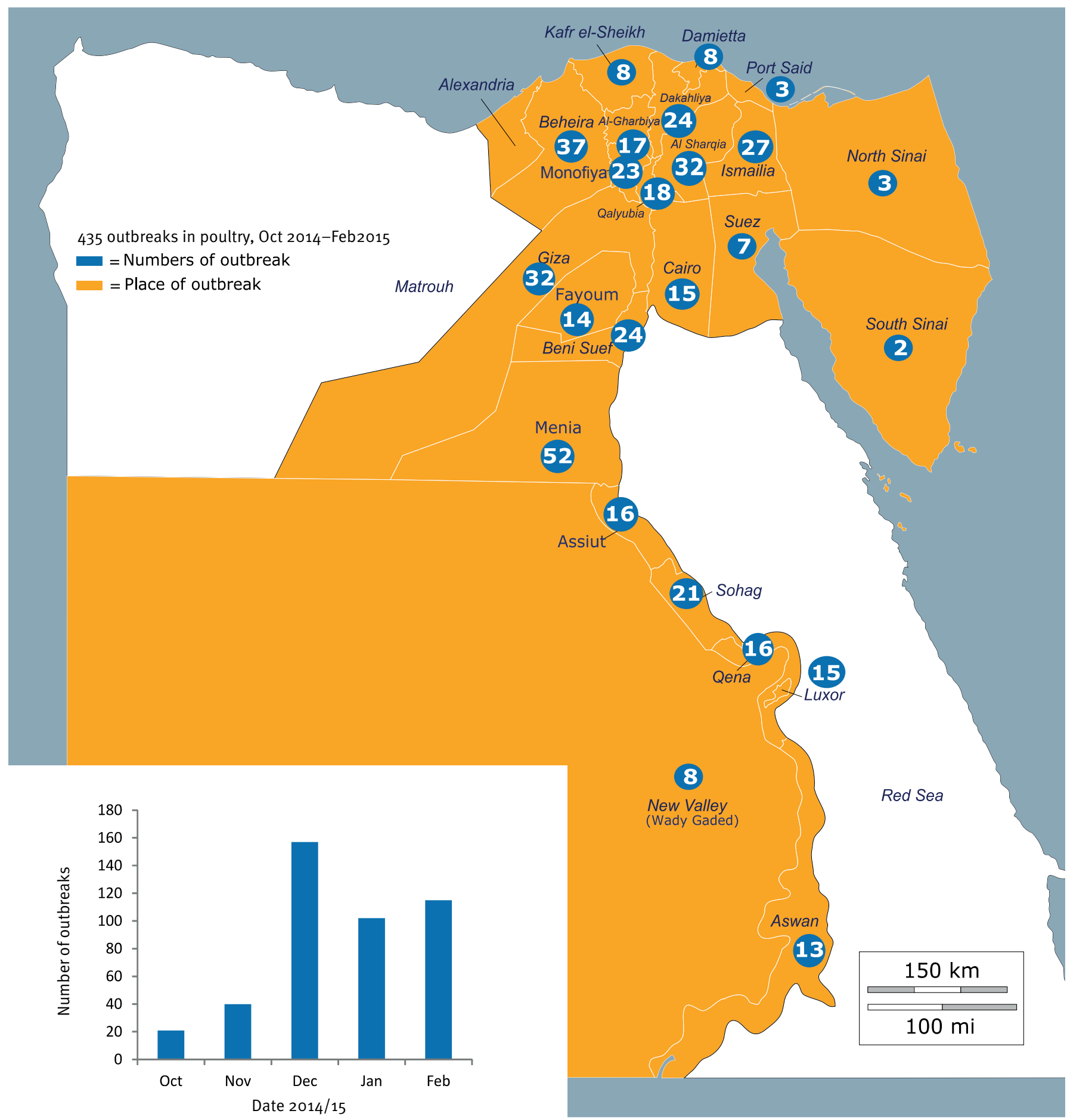

Source of the map: d-maps.com.

Egyptian isolates of 2014. A total of 12 of these mutations were synonymous (silent) and only two resulted in amino acid substitutions (K373R and $\mathrm{F}_{537}$ S). Of these, only $K_{373} R$, located in the stalk domain at the oligomerisation interface of the $\mathrm{HA}$, is characteristic of the emerging cluster; this mutation has sporadically been reported in very few older isolates from Egypt [6].
The mutation $\mathrm{F}_{537 \mathrm{~S}}$ had already been detected in several older isolates. In addition, the HA protein of the viruses in the new cluster contained mutations D $94 \mathrm{~N}$,

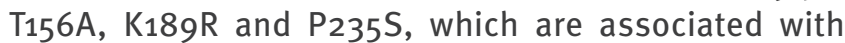
improved binding to SAa2,6-Gal, the human type of influenza virus receptors [7]. However, these mutations were present also in earlier clade 2.2.1 $\mathrm{H}_{5} \mathrm{~N}_{1}$ viruses 


\section{FIGURE 2}

Phylogenetic analysis of the HA (A) and NA (B) genes (coding regions) and maximum clade credibility tree (C) based on the HA open reading frame of selected highly pathogenic avian influenza A(H5N1) viruses, Egypt, June 2014-January 2015 $(n=29)$

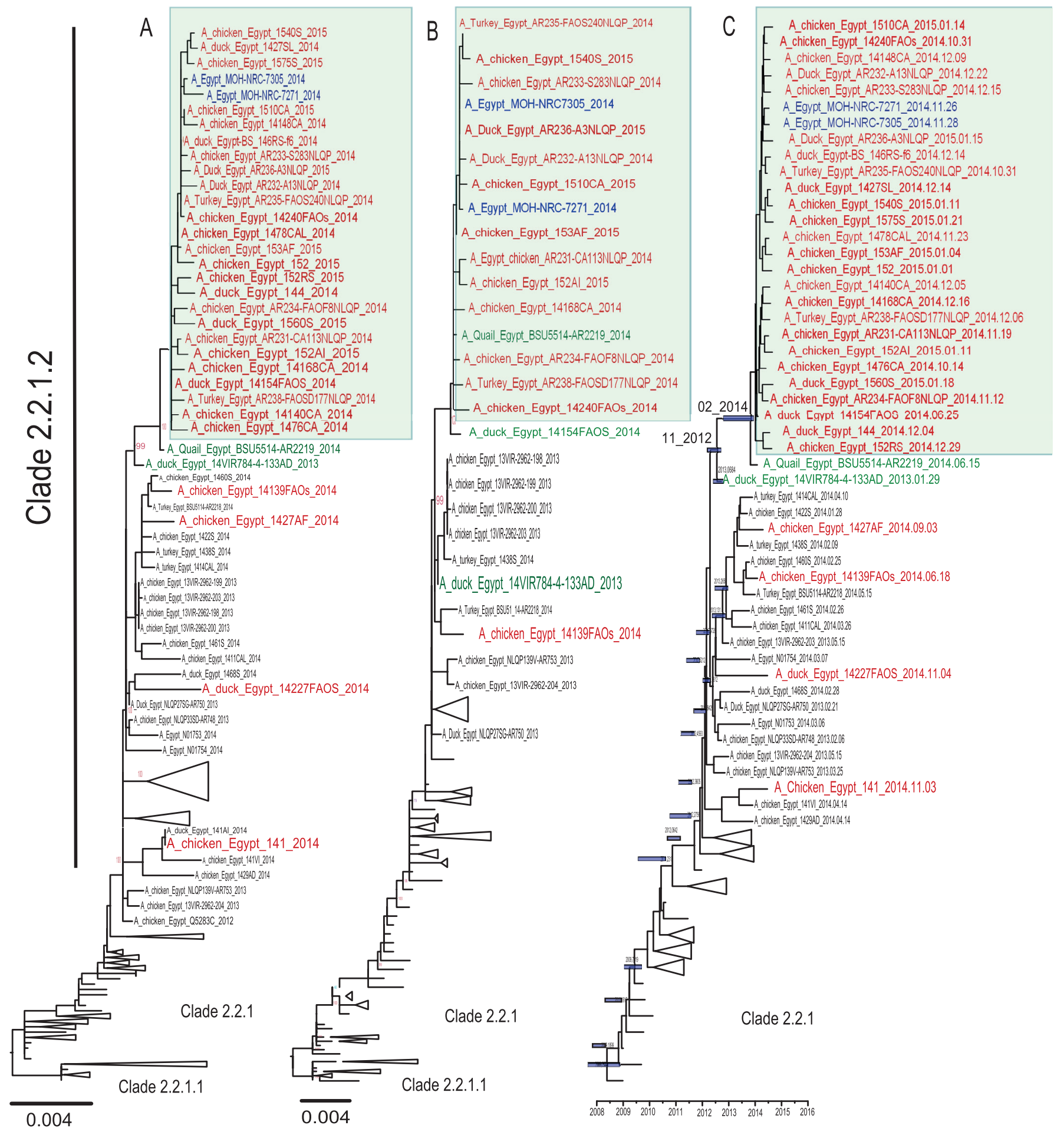

HA: haemagglutinin; NA: neuraminidase.

The phylogenetic analysis was done by maximum likelihood method using the IQTree algorithm [3,4]. BEAST [5] analysis was carried out to determine time to the most recent common ancestor (TMRCA; indicated by horizontal blue bars overlaying nodes). TMRCA calculations were based on an uncorrelated log-normal relaxed clock model. The maximum clade credibility tree was scaled to time using the collection dates (day/month/year) of all samples. Red labels indicate poultry viruses sampled after August 2014 and sequenced in this study. Blue labels denote sequences of viruses retrieved from human influenza $A\left(\mathrm{H}_{5} \mathrm{~N}_{1}\right)$ infections (AJM70734; AJM70746). Green labels highlight viruses close to the basis of the emerging cluster of selected $\mathrm{H}_{5} \mathrm{~N}_{1}$ HPAl viruses circulating in Egypt.

The authors gratefully acknowledge the originating and submitting laboratories who contributed sequences used in the phylogenetic analysis to the Global Initiative on Sharing All Influenza Data (GISAID) EpiFlu database. 
Antigenic characterisation of highly pathogenic avian influenza $\mathrm{A}(\mathrm{H} 5 \mathrm{~N} 1)$ viruses from Egypt and elsewhere, based on haemagglutination inhibition assays

\begin{tabular}{|c|c|c|c|c|c|c|c|c|}
\hline \multirow{3}{*}{$\begin{array}{l}\text { Influenza antigens for } \\
\text { immunisation }\end{array}$} & \multirow{3}{*}{$\begin{array}{l}\text { Immune } \\
\text { sera }\end{array}$} & \multicolumn{2}{|c|}{$\mathrm{H}_{5} \mathrm{LP}$} & \multicolumn{5}{|c|}{$\mathrm{H}_{5} \mathrm{~N}_{1} \mathrm{HP}$} \\
\hline & & $\mathrm{Am}$ & $\mathrm{EA}$ & 2.2 .1 & $2.2 .1 \mathrm{~N}^{\mathrm{a}}$ & 2.2 .1 .1 & 1 & 2.3.2.1 \\
\hline & & $\mathrm{A} / \mathrm{H}_{5} \mathrm{~N}_{2} \mathrm{MX}$ & $\mathrm{A} / \mathrm{H}_{5} \mathrm{~N}_{2} \mathrm{PTD}$ & R740/09 & AR238/15 & R737/09 & NIBRG-14 & $\mathrm{R} 1970 / 13$ \\
\hline \multirow{3}{*}{ A/H ${ }_{5} N_{2} L P$, Mexico vaccine } & $\mathrm{S}_{1}$ & 9 & 8 & 3 & 3 & $\ll 1$ & 7 & $\ll 1$ \\
\hline & S2 & 9 & 7 & 5 & 5 & $\ll 1$ & 5 & 1 \\
\hline & $\mathrm{S}_{3}$ & 10 & 8 & 6 & 5 & $\ll 1$ & 6 & 1 \\
\hline \multirow{3}{*}{ A/ $\mathrm{H}_{5} \mathrm{~N}_{2}$ LP, Potsdam (Germany) } & $\mathrm{S}_{4}$ & 7 & 8 & 5 & 5 & $\ll 1$ & 7 & 3 \\
\hline & $\mathrm{S}_{5}$ & 8 & 10 & 8 & 8 & $\ll 1$ & 8 & 5 \\
\hline & S6 & 7 & 8 & 7 & 6 & $<1$ & 5 & $<1$ \\
\hline $\mathrm{A} / \mathrm{H}_{5} \mathrm{~N}_{1} \mathrm{R} 65$ & $\mathrm{~S} 13$ & 7 & 7 & 8 & 7 & 3 & 7 & 6 \\
\hline \multirow{3}{*}{$\mathrm{A} / \mathrm{H}_{5} \mathrm{~N}_{1} \mathrm{R}_{737}$} & $S_{7}$ & 3 & 4 & 5 & 5 & 9 & 5 & 6 \\
\hline & S8 & 2 & 1 & 5 & 4 & 10 & 4 & 5 \\
\hline & S9 & 2 & $<1$ & 3 & 3 & 10 & 3 & 4 \\
\hline \multirow{3}{*}{$\operatorname{Re}-5$} & $\mathrm{~S}_{10}$ & 6 & 6 & 3 & 3 & $\ll 1$ & 6 & 4 \\
\hline & $\mathrm{S}_{11}$ & 5 & 6 & 4 & 4 & 2 & 6 & 4 \\
\hline & $\mathrm{S}_{12}$ & 4 & 5 & 4 & 4 & 4 & 6 & 4 \\
\hline None & S-SPF & $<1$ & $<1$ & $<1$ & $<1$ & $<1$ & $<1$ & $<1$ \\
\hline
\end{tabular}

Am: American; EA: Eurasian; HP: highly pathogenic; LP: low pathogenic; PTD: Potsdam.

a 2.2.1 $\mathrm{N}$ denotes a virus representative of the currently emerging cluster of highly pathogenic avian influenza $\mathrm{A}\left(\mathrm{H}_{5} \mathrm{~N}_{1}\right)$ viruses in Egypt. Immune sera were raised in chickens against low pathogenic (LP) A/chicken/Mexico/232/1994 (A/H5N2 LP, used as a vaccine virus and representing an American LP H5 strain), against A/duck/Potsdam/1402-6/1986 (A/H5N2 LP PTD, representing an Eurasian LP H5 strain) and against highly pathogenic (HP) A/whooper swan/Germany/R65/2006 (A/H5N1 R65, clade 2.2), A/chicken Egypt/o879-NLQP/2008 (A/H5N1 R737, clade 2.2.1.1) and reverse genetically-modified ( $\mathrm{rg}) \mathrm{A} / \mathrm{duck} / \mathrm{Anhui} / 0.5006$ (Re-5, clade 2.3.4). A specific pathogen-free chicken serum served as negative control. All viruses used for immunisation, except Re-5, also served as antigens in $\mathrm{HI}$ assays. Additional antigens were derived from A/chicken/Egypt/083-NLQP/2008 (R740/09, clade 2.2.1), A/turkey/Egypt/FA0-SD177/2015 (AR238/15, clade 2.2.1, emerging cluster), rg A/Vietnam/1194/2004 (NIBRG-14; clade 1) and A/Hill myna/Austria/R1970/2013 (R1970/13, clade 2.3.2.1). Homologous (same clade) serum-antigen reactions are shown in bold.

in Egypt. Since no substituting mutations were found in HA epitopes, we do not expect marked differences in the antigenic properties of the emerging phylotype compared with the previously circulating clade. This was partially confirmed by haemagglutination inhibition assays using sera against different clades of $\mathrm{H}_{5}$ viruses (Table 2).

The NA gene of the emerging cluster differed by seven nucleotide substitutions from recent $\mathrm{H}_{5} \mathrm{~N}_{1} \mathrm{HPAl}$ viruses of clade 2.2.1.2. Four of the seven mutations encoded amino acid substitutions not previously reported in 2.2.1.2 viruses: $\mathrm{V}_{34} \mathrm{I}, \mathrm{I} 74 \mathrm{~V}, \mathrm{~V} 244 \mathrm{I}$ and $\mathrm{V}_{284} \mathrm{I}$ (Table 3). Mutation $\mathrm{V}_{34} \mathrm{I}$ has been reported in $\mathrm{H}_{5} \mathrm{~N}_{1}$ strains from Cambodia from 2013 where an increase in human $\mathrm{H}_{5} \mathrm{~N}_{1}$ infections was observed [8]. No biological function has been associated with the $\mathrm{V}_{34} \mathrm{l}$ substitution, while positions 74, 244 and 284 are located in B- or T-cell antigenic regions of the NA protein [9].

For four viruses, whole genome sequences were generated and further signature mutations of the emerging viruses were found in the internal gene segments as well: Non-silent cluster-specific mutations were confined to the PB2 (M66I, T106A), PB1-F2 (G22E), and M1 (I15V) proteins (Table 3 ).

\section{Discussion}

Influenza pandemics remain one of the major threats posed by communicable diseases to the human population. The avian reservoir of influenza viruses contributed by reassortment to the emergence of most previous pandemic human influenza viruses [10]. Since their emergence in Asia in 2003, HPAl viruses of subtype $\mathrm{H}_{5} \mathrm{~N}_{1}$ and their recent descendants continue to cause significant economic losses to commercial poultry not only in Asia, but also in Egypt where high mortality in poultry has continuously been observed since $2006[11,12]$. They also exhibit strain-specific zoonotic potential resulting in sporadic avian-to-human spillover transmissions which lead to human infections associated with a high case fatality rate [13]. However, apart from sporadic cases (e.g., family clusters) sustained human-to-human transmission of any of these viruses has not ensued so far.

Our data confirm the emergence of an additional virus cluster within the Egyptian 2.2.1.2 clade of $\mathrm{H}_{5} \mathrm{~N}_{1} \mathrm{HPAl}$ viruses. Since November 2014, viruses of this new cluster appear to have become dominant over the previously described clade 2.2.1.2 phylotypes circulating 


\section{TABLE 3}

Amino acid residues distinguishing recently emerging highly pathogenic avian influenza $\mathrm{A}(\mathrm{H} 5 \mathrm{~N} 1)$ viruses from virus lineages circulating before November 2014, Egypt, March 2015

\begin{tabular}{|l|c|c|c|c|}
\hline Gene segment & Position & $\begin{array}{c}\text { New } \\
\text { cluster }\end{array}$ & $\begin{array}{c}\text { clade } \\
2.2 .1 .2\end{array}$ & $\begin{array}{c}\text { clade } \\
2.2 .1 .1\end{array}$ \\
\hline \multirow{2}{*}{ PB2 } & $66^{\mathrm{a}}$ & $\mathrm{I}$ & $\mathrm{M}$ & $\mathrm{M}$ \\
\cline { 2 - 5 } & $106^{\mathrm{a}}$ & $\mathrm{A}$ & $\mathrm{T}$ & $\mathrm{T}$ \\
\hline PB1-F2 & 22 & $\mathrm{E}$ & $\mathrm{G}$ & $\mathrm{G}$ \\
\hline $\mathrm{HA}$ & $389^{\mathrm{a}}$ & $\mathrm{R}$ & $\mathrm{K}$ & $\mathrm{K}$ \\
\hline \multirow{4}{*}{$\mathrm{NA}$} & 34 & $\mathrm{I}$ & $\mathrm{V}$ & $\mathrm{V}$ \\
\cline { 2 - 5 } & 74 & $\mathrm{~V}$ & $\mathrm{I}$ & $\mathrm{I}$ \\
\cline { 2 - 5 } & 244 & $\mathrm{I}$ & $\mathrm{V}$ & $\mathrm{V}$ \\
\cline { 2 - 5 } & 284 & $\mathrm{I}$ & $\mathrm{V}$ & $\mathrm{V}$ \\
\hline M1 & 15 & $\mathrm{~V}$ & $\mathrm{I}$ & $\mathrm{I}$ \\
\hline
\end{tabular}

HA: haemagglutinin; NA: neuraminidase.

Data on the new cluster are based on sequences established in this study: HA (29 sequences), NA (15 sequences), internal gene segments ( 4 sequences). Data for older clades were retrieved from public databases.

Some of the listed mutations have been infrequently observed among single isolates from previous years.

in various poultry species. The only two publicly available sequences of viruses isolated from recent human $\mathrm{H}_{5} \mathrm{~N}_{1}$ cases in Egypt show similar mutation patterns and fall into the same phylogenetic group. The molecular determinants that may improve the evolutionary fitness of these viruses need to be further clarified. The emergence of new clusters of $\mathrm{H}_{5} \mathrm{~N}_{1}$ HPAl viruses in Egypt is not without precedence: In late 2007, a subclade of antigenic drift variants, later designated 2.2.1.1, emerged and expanded (clade 2.2.1.1a) in commercial poultry in Egypt but disappeared until end of 2010 [14] and, contrary to the current situation, did not replace 2.2.1 viruses. Viruses of clade 2.2.1.1 that emerged in 2007 hardly caused any human cases: according to the OpenFlu database [15]: only one of $100 \mathrm{H}_{5} \mathrm{~N}_{1}$ isolates from humans in Egypt belonged to clade 2.2.1.1; all others belonged to clade 2.2.1 and 2.2.1.2. In contrast, the emerging cluster identified in this study seems to be predominant across all poultry production sectors and has already caused a third of all human infections reported in Egypt since 2006 in only three months of 2015 .

Given the endemic status of influenza $\mathrm{H}_{5} \mathrm{~N}_{1}$ in poultry and the limitations of the reporting system of $\mathrm{H}_{5} \mathrm{~N}_{1}$ HPAI virus outbreaks in poultry in Egypt, it is difficult to assess whether the altered epidemiological pattern of the emerging phylotype is due to altered biological properties in poultry or whether the increased incidence of infections in poultry merely reflects an increased viral burden across all poultry sectors in Egypt. In any case, the observed recent rise in outbreaks in poultry probably resulted in increased exposure risks for humans in contact with poultry, which may have caused an increased incidence in human cases. However, it can at this point not be excluded with certainty that the emerging phylotype of viruses may have increased zoonotic potential and may be transmitted more efficiently to humans, although this assumption cannot be drawn from the molecular evidence described here. Further studies of the pathogenicity and transmissibility of these viruses in humans, e.g. in the ferret model, are required. Concerted efforts of both veterinary and public health authorities are urgently needed to interrupt virus circulation in poultry in Egypt efficiently. This will help decrease the risk of human exposure to the virus.

\section{Acknowledgements}

The authors thank Diana Wessler and Cornelia Illing, FLI, Germany, for excellent technical support. We are grateful to colleagues and co-workers at NLQP, Cairo, Egypt, for providing field samples. M. Naguib is the recipient of a doctoral scholarship from the German Academic Exchange Service (DAAD). This work was supported by funds from the United States Agency for International Development (USAID) obtained under the grant (AID-263-10-11-00001, Mod.\#3) and in the framework of OSRO/EGY/101/USA project, which is jointly implemented by FAO, GOVS and NLQP.

The authors gratefully acknowledge the originating and submitting laboratories who contributed sequences used in the phylogenetic analysis to the Global Initiative on Sharing All Influenza Data (GISAID) EpiFlu database. and recognise in particular Alice Fusaro and colleagues (Istituto Zooprofilattico Sperimentale Delle Venezie, Padova, Italy) as well as Mee Poh (Centers for Disease Control and Prevention, WHO Collaborating Center for Surveillance, Epidemiology and Control of Influenza, Influenza Division, Atlanta, United States). A/Hill myna/Austria/R1970/2013 and NIBRG-14 were kindly provided by $\mathrm{Dr}$ Eveline Wodak/Dr Sandra RevillaFernández, AGES, Vienna, Austria, and the NIBSC, United Kingdom, respectively. Detailed epidemiological information on $\mathrm{H}_{5} \mathrm{~N}_{1}$ outbreaks and on the phylogenetic relationships of internal genome segments are available from the corresponding author on request.

\section{Conflict of interest}

None declared.

\section{Authors' contributions}

Abdel-Satar A. Arafa, Mahmoud M. Naguib and Timm Harder conceived the study. Walid H. Kilany, Ahmed Samy and Ahmed Abdelhalim were involved in the collection, identification and isolation of viruses from field samples. Christine Luttermann, Naglaa Hagag and Abdullah A. Selim conducted the Sanger sequencing. Christian Grund provided data from haemagglutination inhibition assays. Mahmoud M. Naguib, Abdel-Satar A. Arafa, E. M. Abdelwhab and Timm Harder produced, analysed and interpreted genetic and phylogenetic data. Gwenaelle Dauphin, Yilma Makonnen and Mohamed K. Hassan provided and analysed epidemiological data. Timm Harder and Mahmoud M. Naguib drafted the manuscript, Thomas C. Mettenleiter, Martin Beer, Juan Lubroth and all coauthors critically analysed and revised the manuscript and provided final approval. 


\section{References}

1. Abdelwhab EM, Hafez HM. An overview of the epidemic of highly pathogenic $\mathrm{H}_{5} \mathrm{~N} 1$ avian influenza virus in Egypt: epidemiology and control challenges. Epidemiol Infect. 2011;139(5):647-57. http://dx.doi.org/10.1017/ So950268810003122 PMID:21281550

2. World Health Organization (WHO). Avian influenza $A\left(\mathrm{H}_{5} \mathrm{~N}_{1}\right)$ in Egypt update, 21 March 2015. Geneva: WHO. [Accessed: 2 Ap 2015]. Available from: http://www.emro.who.int/surveillanceforecasting-response/surveillance-news/avian-influenza-ah5n1-in-egypt-update-21-march-2015.html

3. Minh $B Q$, Nguyen $M A$, von Haeseler A. Ultrafast approximation for phylogenetic bootstrap. Mol Biol Evol. 2013;30(5):1188-95. http://dx.doi.org/10.1093/molbev/msto24 PMID:23418397

4. Nguyen LT, Schmidt HA, von Haeseler A, Minh BQ. IQTREE: a fast and effective stochastic algorithm for estimating maximum-likelihood phylogenies. Mol Biol Evol. 2015;32(1):268-74. http://dx.doi.org/10.1093/molbev/msu300 PMID:25371430

5. Drummond AJ, Suchard MA, Xie D, Rambaut A. Bayesian phylogenetics with BEAUti and the BEAST 1.7. Mol Biol Evol. 2012;29(8):1969-73. http://dx.doi.org/10.1093/molbev/mss075 PMID:22367748

6. Duvvuri VR, Duvvuri B, Cuff WR, Wu GE, Wu J. Role of positive selection pressure on the evolution of $\mathrm{H}_{5} \mathrm{~N}_{1}$ hemagglutinin. Genomics Proteomics Bioinformatics. 2009;7(1-2):4756. http://dx.doi.org/10.1016/S1672-0229(08)60032-7 PMID:19591791

7. Mertens E, Dugan VG, Stockwell TB, Lindsay LL, Plancarte M, Boyce WM. Evaluation of phenotypic markers in full genome sequences of avian influenza isolates from California. Comp Immunol Microbiol Infect Dis. 2013;36(5):521-36. http://dx.doi. org/10.1016/j.cimid.2013.06.003 PMID:23891310

8. Rith S, Davis CT, Duong V, Sar B, Horm SV, Chin S, et al. Identification of molecular markers associated with alteration of receptor-binding specificity in a novel genotype of highly pathogenic avian influenza $A\left(\mathrm{H}_{5} \mathrm{~N}_{1}\right)$ viruses detected in Cambodia in 2013. J Virol. 2014;88(23):13897-909. http:// dx.doi.org/10.1128/JVI.01887-14 PMID:25210193

9. Gupta SK, Srivastava M, Akhoon BA, Smita S, Schmitz U, Wolkenhauer 0 , et al. Identification of immunogenic consensus T-cell epitopes in globally distributed influenza-A H1 $\mathrm{N}_{1}$ neuraminidase. Infect Genet Evol. 2011;11(2):308-19. http:// dx.doi.org/10.1016/j.meegid.2010.10.013 PMID:21094280

10. Yen HL, Webster RG. Pandemic influenza as a current threat. Curr Top Microbiol Immunol. 2009;333:3-24. http://dx.doi. org/10.1007/978-3-540-92165-3_1 PMID:19768398

11. Abdel-Ghafar AN, Chotpitayasunondh T, Gao Z, Hayden $\mathrm{FG}$, Nguyen DH, de Jong MD, et al. Update on avian influenza $A\left(\mathrm{H}_{5} \mathrm{~N}_{1}\right)$ virus infection in humans. N Engl J Med. 2008;358(3):261-73. http://dx.doi.org/10.1056/NEJMra0707279 PMID:18199865

12. Aly MM, Arafa A, Hassan MK. Epidemiological findings of outbreaks of disease caused by highly pathogenic $\mathrm{H}_{5} \mathrm{~N}_{1}$ avian influenza virus in poultry in Egypt during 2006. Avian Dis. 2008;52(2):269-77. http://dx.doi.org/10.1637/8166-103007Reg.1 PMID:18646456

13. Sonnberg S, Webby RJ, Webster RG. Natural history of highly pathogenic avian influenza $\mathrm{H}_{5} \mathrm{~N} 1$. Virus Res. 2013;178(1):6377. http://dx.doi.org/10.1016/j.virusres.2013.05.009 PMID:23735535

14. Arafa A, Suarez D, Kholosy SG, Hassan MK, Nasef S, Selim $A$, et al. Evolution of highly pathogenic avian influenza $\mathrm{H}_{5} \mathrm{~N}_{1}$ viruses in Egypt indicating progressive adaptation. Arch Virol. 2012;157(10):1931-47. http://dx.doi.org/10.1007/s00705-0121385-9 PMID:22760662

15. Liechti R, Gleizes A, Kuznetsov D, Bougueleret L, Le Mercier $P$, Bairoch A, et al. OpenFluDB, a database for human and animal influenza virus. Database (Oxford). 2010:baq004. http://dx.doi.org/10.1093/database/baq004 PMid:20624713 PMCid:PMC2911839 